\title{
Three Cases of Breast Metastases from Lung Cancer and Systematic Review of the Literature
}

\author{
(D) Nilgün Güldoğan¹, (D) Gül Esen İçten², (10) Fatma Tokat², (D) Burçin Tutar², (iD Halil Kara², (D) Taner Korkmaz², \\ (D) Başak Oyan Uluç ${ }^{2}$, (D) Gökhan Demir ${ }^{2}$ \\ ${ }^{1}$ Clinic of Breast, Acıbadem Altunizade Hospital, İstanbul, Turkey \\ ${ }^{2}$ Institude of Senology, Acıbadem Mehmet Ali Aydınlar University, İstanbul, Turkey
}

\begin{abstract}
Despite the high prevalence of lung cancer among other primary tumors, metastasis of this particular malignancy in the breast is very rare. We report three new cases of lung cancer with breast metastases and discuss radiological and clinical findings. Radiologically, each case displayed different characteristics. First, one of them had bilateral superficially and deeply located irregular lesions. Second, the patient presented with findings similar to inflammatory breast cancer. The third case had a circumscribed mass, resembling a benign complicated cyst. To guide clinicians for proper patient management, radiologists should be aware of the scope of typical and atypical imaging findings of metastatic involvement of the breast.
\end{abstract}

Keywords: Breast neoplasm, breast metastasis, lung cancer, breast ultrasound

Cite this article as: Güldoğan N, Esen İçten G, Tokat F, Tutar B, Kara H, Korkmaz T, Oyan Uluç B, Demir G. Three Cases of Breast Metastases from Lung Cancer and Systematic Review of the Literature. Eur J Breast Health 2021; 17(2): 200-205

\section{Key Points}

- Metastatic tumors in the breast have a wide array of radiological manifestations.

- For pathological confirmation, needle biopsy should be performed for interval lesions in a patient with a known history of lung cancer, even with a probably benign appearance.

- Radiologists should be aware of the range of typical and atypical imaging findings of metastatic involvement of the breast to guide clinicians for proper patient management.

\section{Introduction}

The incidence of metastatic spread from extramammary sites to the breast varies between $0.4 \%$ and $1.3 \%$ of all breast malignancies in clinical series (1-6). The breast is considered to be resistant to metastasis because it contains large areas of fibrous tissue with a relatively low supply of blood $(7,8)$. Most common malignancies that metastasize into the breast are lymphoma, leukemia, and melanoma. Some of the less common primary tumors are carcinomas of the ovary, stomach, and lung, and very rare sources are carcinoid tumors, hypernephromas, and carcinomas of the liver, thyroid, tonsil, pleura, pancreas, cervix, perineum, endometrium, and bladder $(7,9)$.

It is important to differentiate primary from secondary breast malignancies because therapeutic approaches and outcomes are very different. In the literature, various radiological findings have been described. Moreover, there are few detailed imaging reports of metastatic breast lesions from lung cancer. We report three cases of breast metastases from primary lung cancer, each with different radiological findings. We also present a systematic review of the literature covering all cases published in English until 2019.

\section{Case Presentations}

Case 1

A year after she was diagnosed with small-cell lung cancer, a 52-year-old female patient felt a lump in her right breast. The mammograms performed 6 months ago were unremarkable, so the first line of imaging was bilateral whole-breast ultrasound (US). Further, US showed a 
superficially located 9-mm round solid mass with irregular margins and an echogenic halo at 9 o'clock position in the right breast (Figure 1a). On Doppler US imaging, the lesion showed central and peripheral vascularization, which resembled a primary tumor. However, there were two additional irregular Breast Imaging-Reporting and Data System (BIRADS 4) lesions with indistinct margins at 12 o'clock position in the right breast and a well-defined nodule at 9 o'clock position in the left breast. The widths of these lesions, respectively, were $10 \mathrm{~mm}, 3$ $\mathrm{mm}$, and $6 \mathrm{~mm}$. One was superficially located in the subcutaneous fat, and the other two were deep within the parenchyma. One of them was a heterogeneous hyperechoic lesion, and the small lesion had an echogenic rim (Figure 1b). Due to these additional lesions with unusual appearances, the possibility of bilateral breast metastases was considered, and mammography was performed. Mammograms (Figures $2 \mathrm{a}$ and $2 \mathrm{~b}$ ) revealed additional small nodules in both breasts with microlobulated and indistinct margins that were not detected in the US.

Tumor infiltration by small-cell carcinoma was demonstrated by ultrasound-guided core needle biopsy of the index lesion (Figure 3). Moreover, immunohistochemical analysis showed tumor cells positive for synaptophysin, chromogranin, and TTF-1. The tumor displayed high Ki-67 (90\%) proliferation index.

The patient continued chemotherapy, and magnetic resonance imaging (MRI) (Figures 4a and 4e) of the breast revealed progression in the diameter and number of lesions after 6 months. Almost all of them were hyperintense in fat-saturated T2-weighted images (Figures $4 \mathrm{a}$ and $4 \mathrm{~b}$ ). In contrast-enhanced images, most of the lesions showed rim enhancement and type-3 enhancement kinetics (Figures $4 \mathrm{c}$ and $4 \mathrm{~d})$. On the other hand, in diffusion-weighted images, they showed restricted diffusion (Figure 4e).

Following the development of multiple brain metastases, the patient died 18 months after the diagnosis of primary lung cancer and 6 months after the diagnosis of breast metastases.

\section{Case 2}

A 70-year-old female patient who had a strong family history of lung cancer presented with dyspnea. Chest X-ray and consequent computed tomography (CT) scan of the thorax revealed a $26-\mathrm{mm}$ spiculated mass in the anterior segment of the upper lobe of the left lung, followed by bilateral mediastinal and left hilar lymphadenopathies and left pleural effusion. Furthermore, tissue diagnosis of the lung tumor was adenocarcinoma of the lung. Pleural effusion also demonstrated malignant cytology. In addition, brain magnetic resonance imaging
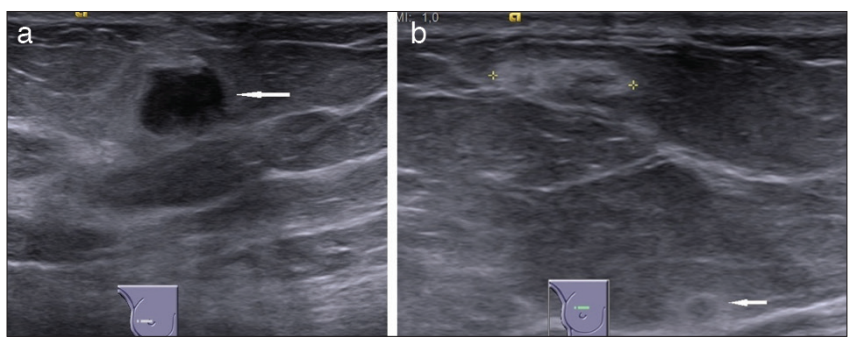

Figure 1. US examination: (a) superficially located irregular solid nodular lesion with echogenic halo at 9 o'clock position in the right breast (arrow). (b) Hyperechoic lesion (in calipers) and a deeply located heterogeneous nodule with an echogenic halo (arrow) at 12 o'clock position in the right breast

US: Ultrasonography
(MRI) revealed additional metastatic lesions in the brain and the left frontal bone. For the brain lesion, she received systemic chemotherapy and stereotactic radiotherapy.

Eight months later, positron emission tomography (PET) scan demonstrated left axillary lymphadenopathy as an interval finding. Two months after this finding and 10 months after the diagnosis of her primary tumor, she detected a lump in her left breast. Mammography revealed skin thickening and trabecular thickening in the lower outer quadrant of the left breast (Figure 5a). On the other hand, US revealed subcutaneous tissue edema, parenchymal distortion, and multiple small vertically oriented irregular hypoechoic non-mass lesions in the lower outer quadrant of the left breast, covering an area of approximately $4 \mathrm{~cm}$ in diameter (Figure 5b). Further, there was evidence of primary inflammatory breast cancer. Ultrasound-guided core needle biopsy of the lesions was then performed. Moreover, hematoxylineosin (H\&E) stained paraffin sections of the breast needle biopsy revealed adenocarcinoma (Figure 6a). The tumor cells demonstrated immunoreactivity for TTF-1 and CK7 and negative immunostain with GATA3, estrogen receptor, and progesterone receptor (Figure 6b). The histopathological findings were consistent with metastasis of pulmonary adenocarcinoma and diffuse intralymphatic spread. Mutational analysis of the tumor in the breast core biopsy specimen demonstrated an L858R mutation in Exon 21 of the EGFR gene. Later on, the patient died 15 months after diagnosis of primary lung cancer and approximately 7 months after breast metastasis was diagnosed.

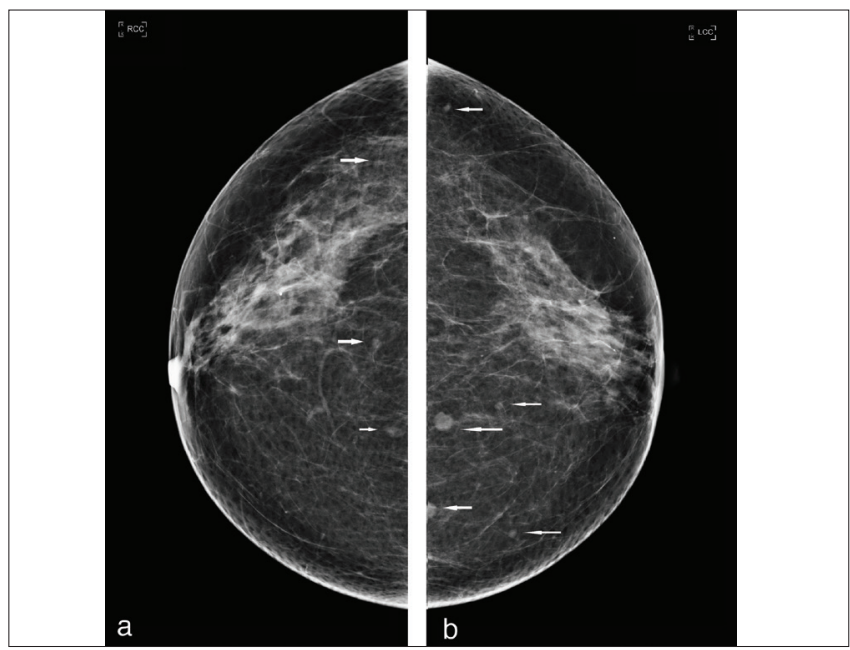

Figure 2. (a,b) Mammography (craniocaudal views) shows multiple nodules smaller than $1 \mathrm{~cm}$ with indistinct/microlobulated margins (arrows)

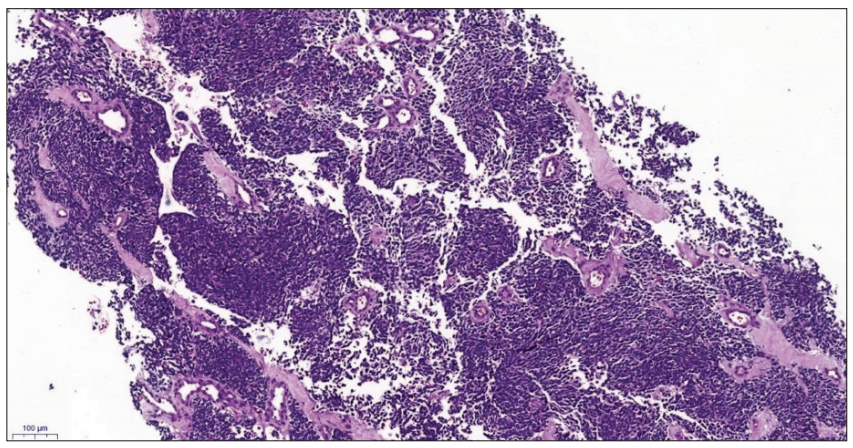

Figure 3. Breast biopsy. Small-cell carcinoma (H\&E)

H\&E: Hematoxylin-eosin 

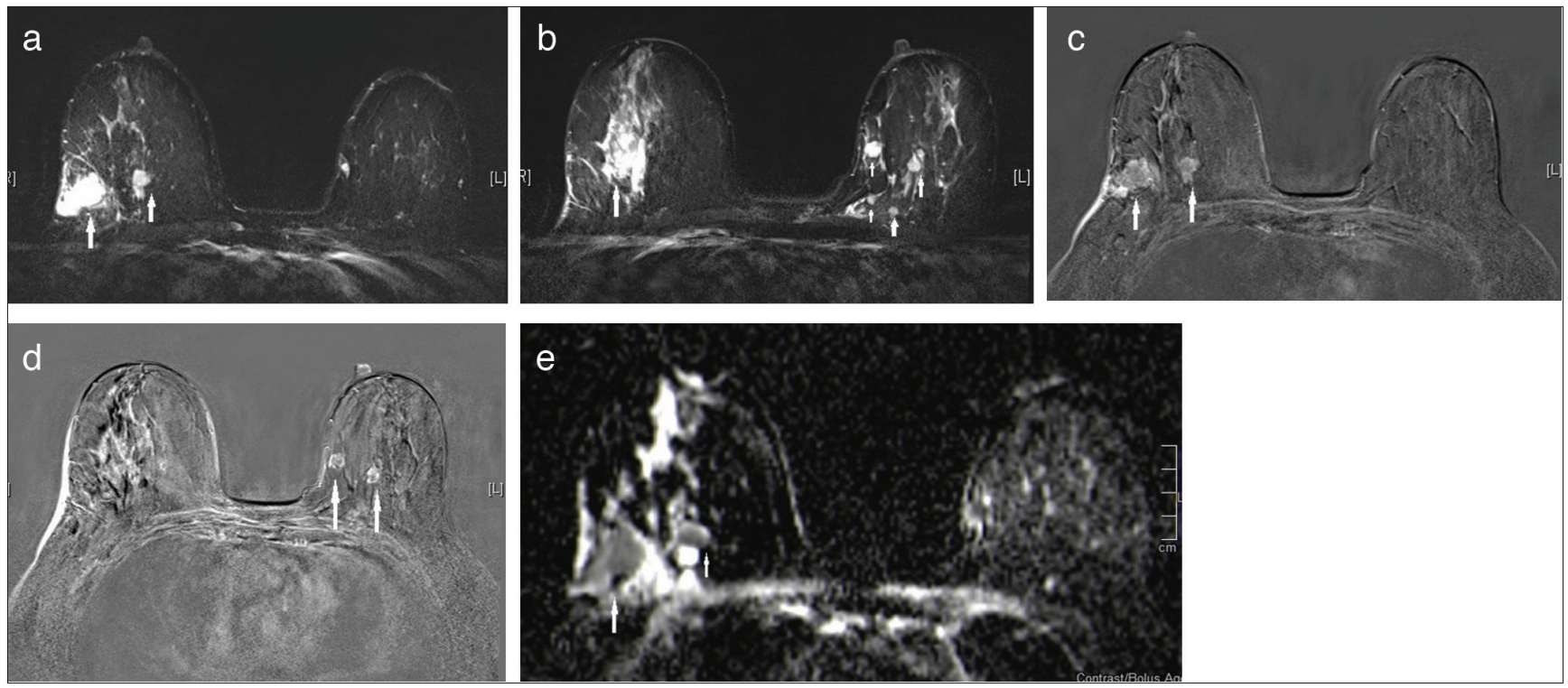

Figure 4. Breast MRI examination. (a-b) Fat-saturated T2-weighted images show bilateral multiple irregular hyperintense nodular lesions (arrows). (c-d) Contrast-enhanced T1-weighted subtraction images: most of the lesions displayed rim enhancement (arrows). (e) Diffusionweighted images ADC map: lesions showed restricted diffusion (arrows)

MRI: Magnetic resonance imaging; ADC: Apparent diffusion coefficient

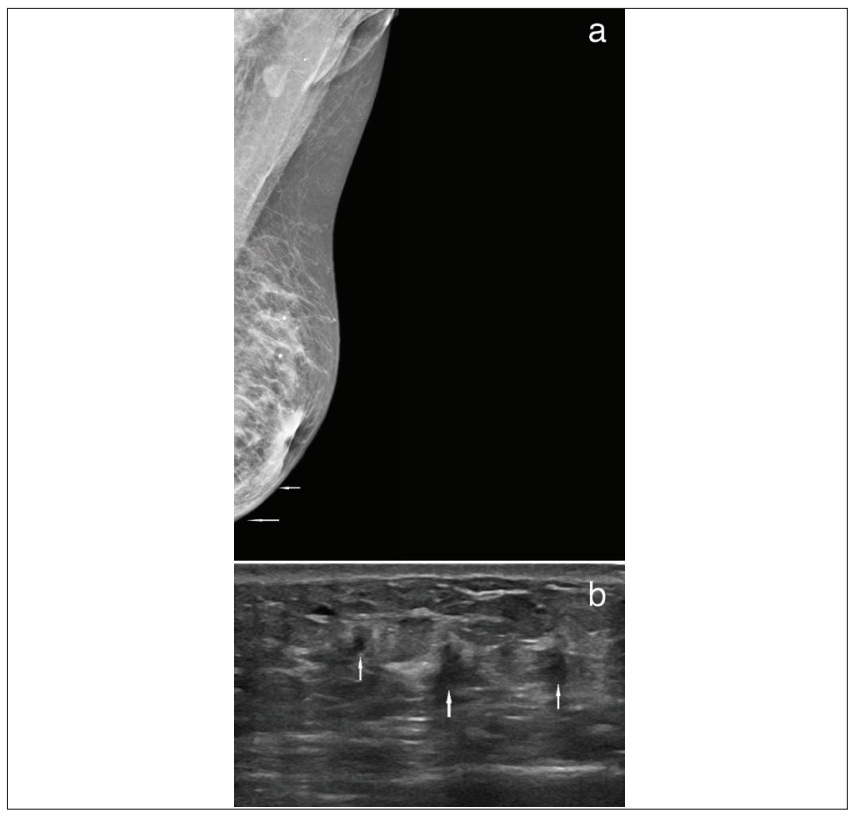

Figure 5. (a) Mammography (left mediolateral oblique view) demonstrates trabecular thickening and skin thickening (arrows) in the lower outer quadrant of the left breast. Retraction of both nipples is noted as incidental finding. (b) Ultrasound of the left breast: irregular, vertically oriented, non-mass lesions (arrows) are seen

\section{Case 3}

A 64-year-old heavy smoker female patient, who had smoked for 40 years and suffered from dyspnea, was diagnosed with a mass in the upper lobe of the left lung. CT scan revealed a centrally located tumor with mediastinal invasion as well as pleural effusion and multiple mediastinal lymphadenopathies. Moreover, the pathological diagnosis was smallcell lung cancer. Ten months after the diagnosis of the primary tumor, a PET scan was performed. In the upper inner quadrant of the left breast,

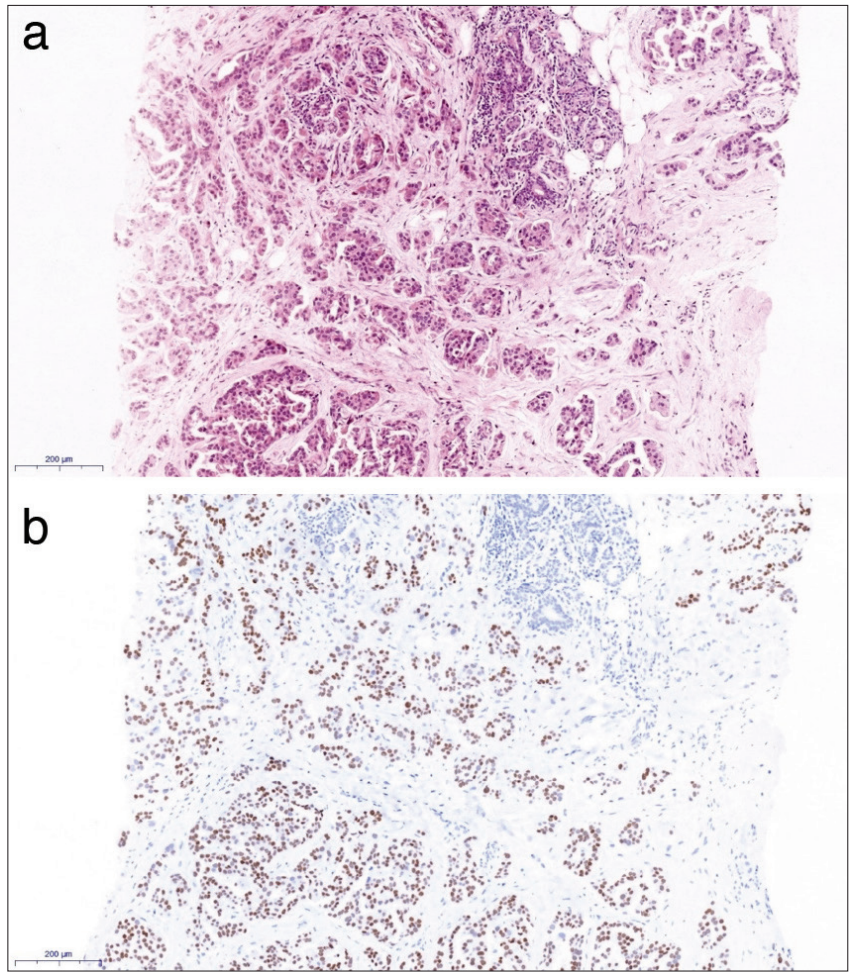

Figure 6. (a) Breast biopsy. Adenocarcinoma (H\&E). (b) Tumor cells positive with TTF-1 immunostain

H\&E: Hematoxylin-eosin

and hypermetabolic nodular lesion were detected. A bilateral breast US examination was performed, showing an 8-mm circumscribed hypoechoic round lesion at 9 o'clock position in the left breast (Figure 7a). At first examination, it resembled a complicated cyst that displayed no internal vascularization. However, a second examination revealed the solid nature of the nodule and an echogenic halo around it, when 
window levels were adjusted (Figure 7b). In addition, US-guided core needle biopsy demonstrated tumor infiltration by small-cell carcinoma (Figure 8). Immunohistochemical analysis showed tumor cells positive for synaptophysin, chromogranin, pan-cytokeratin, and TTF-1. The tumor had a high Ki-67 (95\%) proliferation index. Later on, the patient died 26 months after lung cancer was diagnosed and 16 months after the diagnosis of breast metastasis.

\section{Discussion}

Breast metastases from extramammary sites are very rare. Lung cancer, which is a common malignancy and one of the leading cancer-related
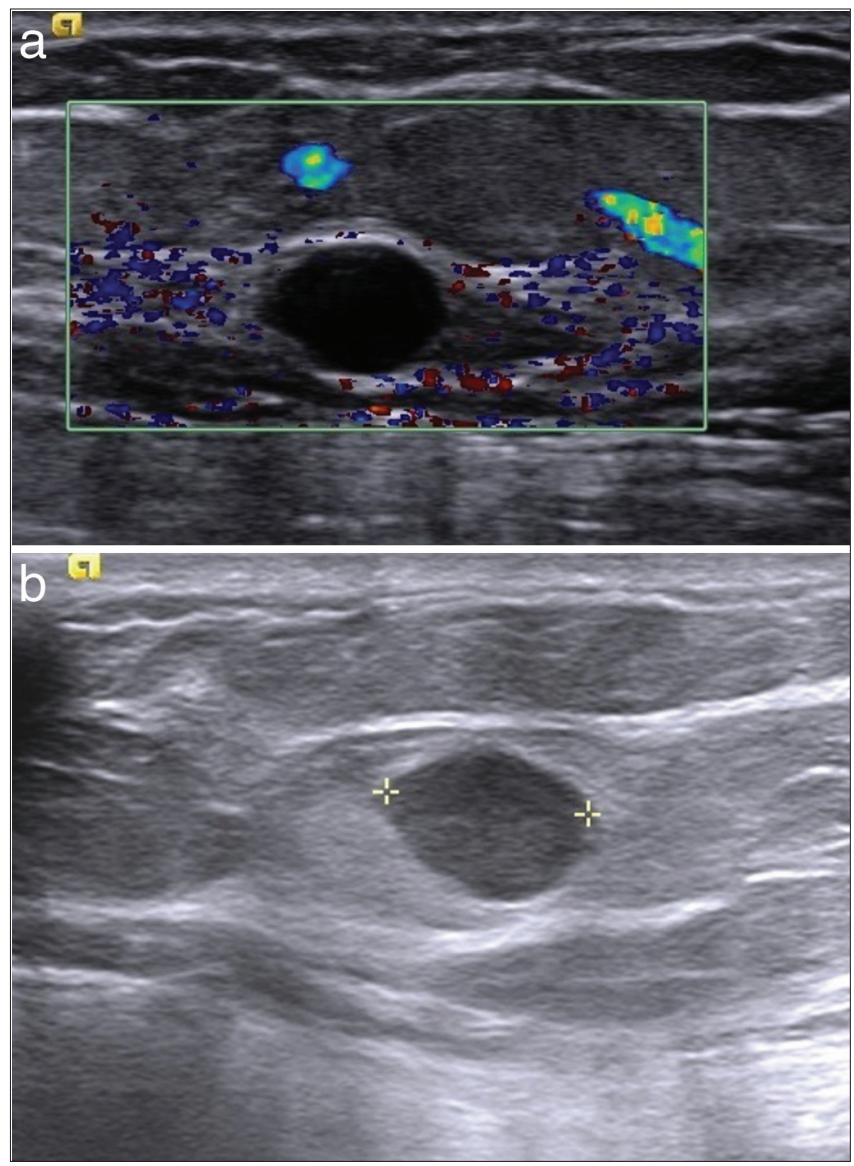

Figure 7. (a) Ultrasound of the left breast: superficially located welldefined cyst-like avascular round lesion. (b) Second US examination revealed the solid nature of the nodule and an echogenic halo

\section{US: Ultrasonography}

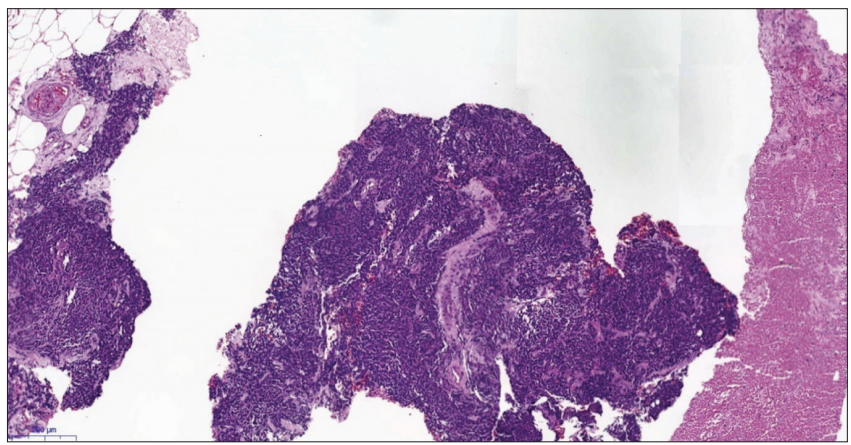

Figure 8. Breast biopsy. Small-cell carcinoma with necrosis (H\&E)

H\&E: Hematoxylin-eosin causes of death worldwide, frequently spreads to other organs but metastasizes to the breast very rarely. A few reviews have previously been published on lung cancer metastasizing to the breast $(3,4,10$ 13). Alva and Shetty Alva (12) reported 78 cases in their literature review from 1855 to 1998 . The most recent and largest review published in 2018 has reported 169 cases from 1999 to 2017 (13). In the cases of Alva and Shetty Alva (12), we have found 180 additional cases of metastatic lung tumors in the breast and made a summary of a total of 258 cases published in English until 2019. Moreover, we could reach the histologic type of lung tumor in 111 cases. Nine of these were identified as non-small-cell lung cancer. The remaining 102 cases were also reported: 61 adenocarcinomas, 14 neuroendocrine tumors, 12 small-cell carcinomas, nine squamous cell carcinomas, two carcinoid tumors, and one each of anaplastic carcinoma, large-cell cancer, pleomorphic carcinoma, and adenosquamous carcinoma.

Metastatic tumors in the breast have a wide variety of radiological appearances. Some may mimic a probably benign lesion, whereas some may be similar to primary breast carcinomas $(3,9)$. Lee et al. (14) also reported that only 2 were classified as BIRADS 3 in their series of 33 cases of breast metastases, the rest being categorized as BIRADS $4 \mathrm{~b}$ or higher. They are usually unilateral and unifocal with a predilection for the upper outer quadrant, but it has been reported that around 33\% can be multifocal and $15 \%$ can be bilateral (15). The most common radiological appearance is a round or oval mass with uncircumscribed margins located superficially in the subcutaneous tissue (10). Lee et al. (16) have stated that around $75 \%$ of cases have irregular margins. Superficial location can be an indication, as primary cancers that arise from the ductal or lobular tissue tend to be deeply located in the parenchyma (1). Although superficially located, unlike primary masses, they do not cause skin or nipple retraction. In secondary tumors, spiculation, posterior shadowing, and calcifications usually detected in primary breast cancers are very rare $(2,3,7$, 16). Calcifications have been identified in metastases of ovarian, gastric, thyroid, and mucin-producing gastrointestinal cancers (14). Metastatic lesions tend to develop rapidly and lack desmoplastic response, which is a typical finding of primary breast cancer (9). Therefore, contrary to primary tumors, an echogenic halo around the mass and parenchymal distortion is not typical characteristics of breast metastases. Nevertheless, two of our cases had an echogenic halo. Moreover, the differential diagnosis of benign and malignant lesions is made easier by the echogenic halo. In case number three, it was evident only after the window level was adjusted, which highlights the significance of meticulous imaging. Echo patterns of metastatic lesions can be homogeneous or heterogeneous (7). Masses may contain cystic areas due to hemorrhage or necrosis. This is more frequently detected in lymphoproliferative lesions as well as gastric, hepatocellular, and ovarian cancers (17). Due to high cellular proliferation, metastatic tumors may also present with a pseudocystic appearance at US. Thus, they may resemble complicated cysts as in one of our cases or triplenegative breast carcinomas (9). As seen in the third case, radiologists should be very cautious before calling these lesions cysts, especially in patients with primary malignancies. Color Doppler US imaging may also be helpful in differentiation.

There are very few studies in the literature on MRI findings for breast metastases. As in the first case, metastatic lesions mostly demonstrate rim enhancement, type-3 enhancement curve, and restricted diffusion on breast MRI, clearly indicating their malignant nature (17). Depending on the presence of necrosis, they can be hypo- or hyperechoic on T2weighted images. In their series of breast metastases, Mun et al. (9) 
have also defined some atypical imaging features, such as non-mass lesions and segmentally or ductally distributed micronodules, similar to the results in our second case.

Depending on the route of disease transmission, clinical and radiological findings of breast metastases may vary (4, 10, 16-18). Hematologically disseminated lesions tend to appear as single or multiple, round to oval, circumscribed, or irregular masses commonly superficially located in subcutaneous tissue or immediately adjacent to the breast parenchyma, which is relatively rich in blood supply (9, 16). Furthermore, axilla is less commonly involved (9). Our first case represents a good example. There were multiple lesions superficially located in the subcutaneous fatty tissue and additional lesions deep in the parenchyma. Tumors that spread through the lymphatic route tend to manifest in the subcutaneous lymphatic channels as skin thickening, subcutaneous edema, and trabecular thickening due to tumor emboli (2). An apparent mass may or may not be present ( 9 , 17). Mammography usually indicates asymmetric opacity, and MRI may demonstrate non-mass enhancement and edema. Clinically, peau d'orange and redness on the skin may occasionally be observed. These cases can be falsely diagnosed as mastitis or inflammatory breast cancers $(2,4)$. It has been documented that ovarian, gastric, and lung cancers lead to this type of breast metastases $(4,16,19,20)$. Huang et al. (11) reported that pleural effusion, pleural thickening, and ipsilateral axillary lymphadenopathy precede the development of breast lesions in lung cancers that spread through the lymphatic route to the breast. They have also indicated that the breast is affected in a retrograde fashion after the intervention of the axilla. In our second case, radiological findings are probably consistent with this type of dissemination. In lung cancer patients with pleural effusion, the axilla and the breast should be closely examined. Another means of spreading lung cancer to the breast can be through direct chest wall invasion, but this is not a common finding.

There are no specific predisposing factors associated with breast metastases. It has been postulated that by increasing the vascularity of the breast, estrogen may have a role as a predisposing factor in the development of metastasis. This has been proposed as an explanation for the relatively higher incidence of breast metastases in young women $(9,16)$. In contradiction to this hypothesis, all of our patients were postmenopausal women. Clinically, the presenting symptom was palpable breast lump in two of our three cases in accordance with the literature (2). In one case, the breast mass was an incidental finding in the PET-CT.

In conclusion, breast metastases from lung cancer are very rare, but it is clinically very important to distinguish primary from metastatic breast lesions. It is also important to apply the necessary chemotherapeutic regimens for metastatic patients and to guide them correctly in their disease prognosis while avoiding unnecessary surgical treatments. In this article, we present a literature review as well as three new cases, each with distinct radiological appearances. These cases support other studies of breast metastases, demonstrating a variety of radiological findings. Due to the lack of specific radiological features, immunohistochemical studies are important to reach an accurate diagnosis.

Informed Consent: Informed consent was received.

Peer-review: Externally-peer reviewed.

\section{Authorship Contributions}

Concept: N.G.; Design: N.G., G.E.İ.; Supervision: G.E.I.; Materials: N.G., G.E.İ., F.T., B.T., H.K., T.K., B.O.U., G.D.; Data Collection and/or Processing: N.G., F.T., B.T., H.K., T.K., B.O.U., G.D.; Analysis and/or Interpretation: N.G., G.E.I., F.T.; Literature Search: N.G., G.E.İ.; Writing Manuscript: N.G., G.E.I., F.T.; Critical Review: G.E.İ.

Conflict of Interest: No conflict of interest was declared by the authors.

Financial Disclosure: The authors declared that this study received no financial support.

\section{References}

1. Babu KS, Roberts F, Bryden F, McCafferty A, Downer P, Hansell DT, et al. Metastases to breast from primary lung cancer. J Thorac Oncol 2009; 4: 540-542. (PMID: 19333072) [CrossRef]

2. Maounis N, Chorti M, Legaki S, Ellina E, Emmanouilidou A, Demonakou M, et al. Metastasis to the breast from an adenocarcinoma of the lung with extensive micropapillary component: a case report and review of the literature. Diagn Pathol 2010; 5: 82-87. (PMID: 21167048) [CrossRef]

3. Wang L, Wang SL, Shen HH, Niu FT, Niu Y. Breast metastasis from lung cancer: a report of two cases and literature review. Cancer Biol Med 2014; 11: 208-215. (PMID: 25364582) [CrossRef]

4. Ota T, Hasegawa Y, Okimura A, Sakashita K, Sunami T, Yukimoto K, et al. Breast metastasis from EGFR-mutated lung adenocarcinoma: A case report and review of the literature. Clin Case Rep 2018; 6: 1510-1516. (PMID: 30147894) [CrossRef]

5. Georgiannos SN, Chin J, Goode AW, Sheaf M. Secondary Neoplasms of the breast: A survey of the 20 ${ }^{\text {th }}$ Century. Cancer 2001; 92: 2259-2266. (PMID: 11745279) [CrossRef]

6. Klingen TA, Klaasen H, Secondary breast cancer: A 5-year populationbased study with review of the literature. APMIS 2009; 117: 762-727. (PMID: 19775345) [CrossRef]

7. Yeh $\mathrm{CN}$, Lin $\mathrm{CH}$, Chen MF. Clinical and ultrasonographic characteristics of breast metastases from extramammary malignancies. Am Surg 2004; 70: 287-290. (PMID: 15098776) [CrossRef]

8. Shen YW, Sui YX, Zhang XM, Meng LV, Zhang X, Liu PJ, et al. Ipsilateral breast metastasis from a pulmonary adenocarcinoma: a case report and a focused review of the literature. Int J Clin Exp Pathol 2015; 8: 96479654. (PMID: 26464732) [CrossRef]

9. Mun SH, Ko EY, Han BK, Shin JH, Kim SJ, Cho EY. Breast metastases from extramammary malignancies: typical and atypical ultrasound features. Korean J Radiol 2014; 15: 20-28. (PMID: 24497788) [CrossRef]

10. Gao Q, Wang B, Zheng Y, Ren G, Zhou J. Breast metastasis from lung cancer: report of two cases of adenocarcinoma with different gene mutation and one case of squamous cell carcinoma. Int J Clin Exp Pathol 2016; 9: 443-453. [CrossRef]

11. Huang HC, Hang JF, Wu MH, Chou TY, Chiu CH. Lung adenocarcinoma with ipsilateral breast metastasis: a simple coincidence? J Thorac Oncol 2013; 8: 974-979. (PMID: 23774384) [CrossRef]

12. Alva S, Shetty Alva N. An uptade of tumor metastasis to the breast data. Arch Surg 1999; 134: 450. (PMID: 10199322) [CrossRef]

13. Ali RH, Taraboanta C, Mohammad T, Hayes MM, Ionescu D. Metastatic non-small cell lung carcinoma a mimic of primary breast carcinoma-case series and literature review. Virchow's Arch 2018; 472: 771-777. (PMID: 29105026) [CrossRef]

14. Lee SK, Kim WW, Kim SH, Hur SM, Kim S, Choi JH, et al. Characteristics of metastasis in the breast from extramammary malignancies. J Surg Oncol 2010; 101: 137-140. (PMID: 20082359) [CrossRef] 


\section{Güldoğan et al. Breast Metastases from Lung Cancer}

15. Williams SA, Ehlers RA $2^{\text {nd }}$, Hunt KK, Yi M, Kuerer HM, Singletary SE, et al. Metastases to the breast from nonbreast solid neoplasms: presentation and determinants of survival. Cancer 2007; 110: 731-737. (PMID: 17582626) [CrossRef]

16. Lee SH, Park JM, Kook SH, Han BK, Moon WK. Metastatic tumors to the breast: mammographic and ultrasonographic findings. J Ultrasound Med 2000; 19: 257-262. (PMID: 10759349) [CrossRef]

17. Lee JH, Kim SH, Kang BJ, Cha ES, Kim HS, Choi JJ. Metastases to the breast from extramammary malignancies - sonographic features. J Clin Ultrasound 2011; 39: 248-255. (PMID: 21469153) [CrossRef]
18. Bitencourt AGV, Gama RRM, Graziano L, Negráo EMS, Sabino SMPS, Watanabe AHU, et al. Breast metastases from extramammary malignancies: multimodality imaging aspects. Br J Radiol 2017; 90: 2017-2197. (PMID: 28485985) [CrossRef]

19. Ozgüroğlu M, Ersavaşti G, Ilvan S, Hatemi G, Demir G, Demirelli FH. Bilateral inflammatory breast metastases of epithelial ovarian cancer. Am J Clin Oncol 1999; 22: 408-410. (PMID: 10440201) [CrossRef]

20. Kayikçioğlu F,Boran N, Ayhan A, Güler N. Inflammatory breast metastases of ovarian cancer: A case report. Gynecol Oncol 2001; 83: 613-616. (PMID: 11733984) [CrossRef] 